\title{
Mitral valve replacement in infants
} and younger children

\author{
Ahmed F. Elmahrouk ${ }^{1,2 \bowtie}$, Mohamed H. Mashali ${ }^{3,4}$, Mohamed F. Ismail ${ }^{1,5}$, Amr A. Arafat ${ }^{2}$, \\ Rawan M. Alamri' ${ }^{1}$, Haysam A. Baho ${ }^{3}$, Mohammad S. Shihata ${ }^{1}$ \& Ahmed A. Jamjoom ${ }^{1}$
}

Data on mitral valve replacement (MVR) in young children is still limited. Our objective was to evaluate MVR in children below 5 years and identify factors affecting the outcomes. This retrospective study included 29 patients who had MVR from 2002 to 2020 . We grouped the patients into two groups according to their age: age $\leq 24$ months $(n=18)$ and $>24$ months $(n=11)$. Primary cardiac diagnoses were Shone complex $(n=7 ; 24 \%)$, isolated congenital mitral valve abnormality $(n=11 ; 38 \%)$, and complete atrioventricular septal defect $(n=3 ; 10 \%)$. The median age was 19 month (25th-75th percentile: $11-32)$ and $59 \%$ were females $(n=17)$. The hemodynamic lesions were mitral regurgitation in $66 \%$, mitral stenosis in $10 \%$, and combined mitral stenosis and regurgitation in $24 \%$ of the patients. St. Jude mitral valve was the most common valve implanted $(n=19,66 \%)$, followed by CarboMedics in $21 \%$ of the patients $(n=6)$. The mitral valve was implanted in the supra-annular position in 6 cases (21\%). Preoperative and operative data were comparable between both groups. There was no association between valve size and position with postoperative heart block ( $P>0.99$, for both). The median follow-up duration was 19.4 months (8.6-102.5). Nine patients had mitral valve reoperation, six had MVR, and three had clot removal from the mitral valve. There was no effect for age group on reoperation (SHR $0.89(95 \% \mathrm{Cl} 0.27-2.87), \mathrm{P}=0.84)$. Valve size significantly affected reoperation (SHR $0.39(95 \% \mathrm{Cl} 0.18-0.87), \mathrm{P}=0.02)$. The supra-annular position was associated with an increased risk of reoperation (SHR $3.1(95 \% \mathrm{Cl} 1.003-9.4), \mathrm{P}=0.049)$. There was no difference in survival according to the age ( $\log$-rank $P=0.57$ ) or valve size (Log-rank $P=0.66$ ). Mitral valve replacement in children is associated with low morbidity and mortality. The risk of reoperation could be affected by the valve size and position rather than the age.

Mitral valve repair is the recommended treatment strategy for infants and children with surgical mitral valve (MV) disease; however, mitral valve replacement (MVR) is performed when mitral valve repair is not anatomically feasible ${ }^{1}$ The decision to perform MVR in young children is difficult ${ }^{2}$. Studies reporting the outcomes of MVR in children are limited by the sample size, inclusion of a wide range of ages, and the single-center experience ${ }^{3}$.

MVR in children has several limitations, and it is associated with a high mortality rate ranging from 10 to $36 \%{ }^{4}$. Moreover, long-term anticoagulation therapy is associated with increased morbidity, in addition to the risk of repeat MVR as the child grows ${ }^{5}$. The outcomes after MVR in children under 5 years are still controversial. We aimed to evaluate our experience with mitral valve replacement in infants and young children less than 5 years old and identify factors affecting the outcomes.

\section{Patient and methods}

Design and patients. We performed a retrospective study including patients who underwent MVR at King Faisal Specialist and Research Center, Jeddah, between May 2002 and December 2020. We included patients aged 5 years or younger. Patients who had prior MVR performed outside the center were excluded. All patients had elective MVR. We grouped the patients into two groups according to their age: age $\leq 24$ months $(n=18)$ and age $>24$ months and $\leq 60(n=11)$. Primary cardiac diagnoses were Shone complex in seven cases $(24 \%)$, isolated congenital MV abnormality in eleven cases (38\%), and complete atrioventricular septal defect in three cases (10\%). The study was approved by the Institutional Review Board of King Faisal Specialist Hospital and Research Center with (Registration number: 2020-105). All procedures in this study were carried out after prior

${ }^{1}$ Division of Cardiac Surgery, Cardiovascular Department, King Faisal Specialist Hospital and Research Center, MBC J-16, P.O. Box: 40047, Jeddah 21499, Saudi Arabia. ${ }^{2}$ Cardiothoracic Surgery Department, Tanta University, Tanta, Egypt. ${ }^{3}$ Pediatric Cardiology Department, King Faisal Specialist Hospital and Research Center, Jeddah, Saudi Arabia. ${ }^{4}$ Department of Pediatrics, Faculty of Medicine, Cairo University, Cairo, Egypt. ${ }^{5}$ Cardiothoracic Surgery Department, Mansoura University, Mansoura, Egypt. ${ }^{\circledR}$ email: Ael-mahrouk@kfshrc.edu.sa 
informed consent from patients' guardians, in accordance with relevant guidelines and regulations. The need for the guardians' consent for publication was waived due to the retrospective nature of the study.

Study data and outcomes. We collected the preoperative, operative, and postoperative data required for this study from electronic and paper medical records. Operative data included the mitral valve position, type, and size. Study outcomes were hospital complications, reoperation, and long-term survival. Hospital outcomes were defined as those occurring during the indexed hospitalization or within 30 days from surgery. Follow-up of the patients was recorded until December 2020.

Postoperative anticoagulation regimen. Postoperatively, patients were anticoagulated with warfarin with a target international normalization ratio (INR) of 2.5-3.5. We started heparin infusion within $24 \mathrm{~h}$ postoperatively as bridging anticoagulation. INR was measured and reported daily until the target level was achieved, then every seven days following discharge. Patients were followed after discharge in the anticoagulation outpatient clinic. Two patients were shifted to low molecular weight heparin due to postoperative bleeding with Activated Factor X monitoring and shifted back to warfarin after completing the first year of life. Supplementary antiplatelet therapy "Aspirin" was used in the first six months postoperatively in selected cases.

Statistical analysis. We compared qualitative data using the Chi-square or Fisher exact test if the expected frequency was less than 5 , and data were presented as numbers (\%). The quantitative variables were compared using the $t$ test if normally distributed or the Mann-Whitney test if non-normally distributed. Normally distributed data were presented as mean and standard deviation and non-normal data as median (25th-75th percentiles). Correlation was assessed with Spearman test. Time to event outcomes were compared using the Log-rank test, and their distribution was plotted with the Kaplan-Meier method. Death was considered a competing risk for mitral valve reoperations. The Fine and Gray method was used to perform competing risk regression, and the cumulative incidence was plotted. We used STATA 16.1 (Stata Corp, College Station, TX, USA) to perform all analyses.

Ethics approval. The study was approved by the institutional review board (IRB) of King Faisal specialist hospital and research center, Jeddah, Saudi Arabia, under approval number: IRB\# 2020-105.

Consent to participate. All procedures in this study were carried out after prior informed consent from patients' guardians, in accordance with relevant guidelines and regulations.

\section{Results}

Preoperative and operative data. The median age of our sample was 19 month (25th-75th percentile: $11-32) ; 59 \%$ were females $(\mathrm{n}=17)$. Mitral valve pathology included parachute MV in 4 cases $(14 \%)$, absent and short chordae in 3 cases (10\%). Eight patients (28\%) had previous operative attempts of mitral valve repair. Mitral valve regurgitation was the most common lesion. St. Jude mitral valve was the most common valve implanted $(n=19,65.5 \%)$, followed by CarboMedics in $21 \%$ of the patients $(n=6)$. The size of MV used was less than $17 \mathrm{~mm}$ in $38 \%, 17-21 \mathrm{~mm}$ in $45 \%$, and more than $21 \mathrm{~mm}$ in $17 \%$ of cases. The mitral valve was put in supra-annular position in six cases $(21 \%)$. There was no correlation between the valve size, age $(\mathrm{P}=0.80)$ or body surface area $(\mathrm{P}=0.09)$. Preoperative and operative data are presented in Table 1 .

Postoperative outcomes. The median hospital stay was 14 days. Early mortality occurred in two patients (7\%). (Table 2) The valve size and position did not affect the rate of postoperative heart block $(\mathrm{P}>0.99$, for both). Postoperative bleeding was not associated with the age group $(\mathrm{P}=0.35)$, valve position $(\mathrm{P}=0.32)$ or valve size $(P=0.71)$. Postoperative thrombosis or stroke were not associated with the age group $(P>0.99)$, valve position $(\mathrm{P}=0.43)$, or valve size $(\mathrm{P}=0.63)$.

Long-term outcomes. The median follow-up duration was 19.4 months (8.6-102.5). Survival was $93 \%$ at 1 year and $88 \%$ at 5 years. Among survivors, the 5 -year freedom from reoperation was $81 \%$. Nine patients had mitral valve reoperation (Five in Group 1 and four in Group 2). Six had MVR (three in each group), and three had clot removal from the mitral valve (two in Group 1 and one in Group 2). In addition, two patients underwent a second MVR. Mitral valve sizes used in the first reoperation were $25 \mathrm{~mm}(\mathrm{n}=1), 21 \mathrm{~mm}(\mathrm{n}=2)$, and $19 \mathrm{~mm}(\mathrm{n}=3)$. All patients had a larger-sized valve than their initial MVR except one patient with a dysfunctional mechanical valve and had the same size valve $(19 \mathrm{~mm})$, which was suitable for his body surface area. Patients with valve thrombosis had follow-ups in peripheral centers, and their INR records were not available.

Competing risk analysis was performed to evaluate the effect of age on reoperation in the presence of death as a competing variable. We did not find effect of age group on reoperation (sub-hazard ratio (SHR) 0.89 (95\% CI 0.27-2.87), $\mathrm{P}=0.84$ ) (Fig. 1). Valve size significantly affected reoperation (SHR 0.39 (95\% CI 0.18-0.87), $\mathrm{P}=0.02)$ (Fig. 2). Supra-annular position was associated with increased the risk of reoperation (SHR $3.1(95 \%$ CI 1.003-9.4), $\mathrm{P}=0.049)$ (Fig. 3). The preoperative diagnosis did not affect valve reoperation (SHR $1.14(95 \%$ CI $0.52-2.46), \mathrm{P}=0.74)$.

We did not find differences in survival according to the age (Log-rank $\mathrm{P}=0.57)$ (Fig. 4), valve size (Log-rank $\mathrm{P}=0.66$ ) (Fig. 5), valve pathology (log-rank $\mathrm{P}=0.39$ ), diagnosis (Log-rank $\mathrm{P}=0.49)$ and valve position (Log$\operatorname{rank} \mathrm{P}=0.16)$. 
\begin{tabular}{|l|l|l|l} 
All patients $(n=29)$ & Age $\leq 24$ months $(n=18)$ & Age $>24$ months and $\leq 60(n=11)$ & P
\end{tabular}

\begin{tabular}{|c|c|c|c|c|}
\hline \multicolumn{5}{|l|}{ Preoperative data } \\
\hline Age (months) & $19(11-32)$ & $11(6-15)$ & $40(30-48)$ & $<0.001$ \\
\hline Female & $17(58.6 \%)$ & $9(50 \%)$ & $8(72.7 \%)$ & 0.27 \\
\hline Body weight $(\mathrm{Kg})$ & $9.3(8.3-13)$ & $9(7.9-11)$ & $12.2(10.8-13.3)$ & 0.08 \\
\hline Body surface area $\left(\mathrm{m}^{2}\right)$ & $0.43(0.30-0.53)$ & $0.38(0.27-0.46)$ & $0.52(0.44-0.59)$ & 0.03 \\
\hline Associated non-cardiac anomalies & $3(10.3 \%)$ & $1(5.6 \%)$ & $2(18.2 \%)$ & 0.54 \\
\hline \multirow{4}{*}{ Non cardiac surgery } & \multirow{4}{*}{$3(10.3 \%)$} & $3(16.7 \%)$ & \multirow{4}{*}{0} & \multirow{4}{*}{0.27} \\
\hline & & Orchidopexy & & \\
\hline & & Pyloroplasty & & \\
\hline & & Ilium perforation & & \\
\hline Down syndrome & $4(13.8 \%)$ & $3(16.7 \%)$ & $1(9.1 \%)$ & $>0.99$ \\
\hline \multicolumn{4}{|l|}{ Diagnosis } & \multirow{5}{*}{0.75} \\
\hline Shone's complex & $7(24.1 \%)$ & $3(16.7 \%)$ & $4(36.4 \%)$ & \\
\hline Congenital MR & $11(37.9 \%)$ & $8(44.4 \%)$ & $3(27.3 \%)$ & \\
\hline AV canal & $3(10.3 \%)$ & $2(11.1 \%)$ & $1(9.1 \%)$ & \\
\hline Others $^{*}$ & $8(27.6 \%)$ & $5(27.8 \%)$ & $3(27.3 \%)$ & \\
\hline \multicolumn{5}{|l|}{ MV pathology } \\
\hline Parachute MV & $4(13.8 \%)$ & $3(16.7 \%)$ & $1(9.1 \%)$ & $>0.99$ \\
\hline Displaced papillary muscle & $1(3.5 \%)$ & 0 & $1(9.1 \%)$ & 0.38 \\
\hline Absent or short chordae & $3(10.3 \%)$ & $2(11.1 \%)$ & $1(9.1 \%)$ & $>0.99$ \\
\hline \multicolumn{4}{|l|}{ MV lesion } & \multirow{4}{*}{0.71} \\
\hline Stenosis & $3(10.3 \%)$ & $1(5.6 \%)$ & $2(18.2 \%)$ & \\
\hline Regurgitation & $19(65.5 \%)$ & $12(66.7 \%)$ & $7(63.6 \%)$ & \\
\hline Double & $7(24.1 \%)$ & $5(27.8 \%)$ & $2(18.2 \%)$ & \\
\hline PHT & $4(13.8 \%)$ & $4(22.2 \%)$ & 0 & 0.27 \\
\hline Mean gradient & $16(7-20)$ & $7(6-13)$ & $19.5(18-22)$ & 0.002 \\
\hline \multicolumn{5}{|l|}{ Operative details } \\
\hline Posterior leaflet preservation & $3(10.3 \%)$ & $2(11.1 \%)$ & $1(9.1 \%)$ & $>0.99$ \\
\hline \multicolumn{5}{|l|}{ Size of the valve $(\mathrm{mm})$} \\
\hline 16 & $5(17.24 \%)$ & $3(16.67 \%)$ & $2(18.18 \%)$ & \multirow{9}{*}{0.66} \\
\hline 17 & $6(20.69 \%)$ & $4(22.22 \%)$ & $2(18.18 \%)$ & \\
\hline 18 & $2(6.90 \%)$ & $1(5.56 \%)$ & $1(9.99 \%)$ & \\
\hline 19 & $5(17.24 \%)$ & $4(22.22 \%)$ & $1(9.09 \%)$ & \\
\hline 21 & $6(20.69 \%)$ & $2(11.11 \%)$ & $4(36.36 \%)$ & \\
\hline 23 & $2(6.90 \%)$ & $2(11.11 \%)$ & 0 & \\
\hline 24 & $1(3.45 \%)$ & $1(5.56 \%)$ & 0 & \\
\hline 25 & $1(3.45 \%)$ & $1(5.56 \%)$ & 0 & \\
\hline 27 & $1(3.45 \%)$ & 0 & $1(9.09 \%)$ & \\
\hline $\mathrm{CPB}(\min )$ & $112.5(94-160)$ & $118(79-178)$ & $106(94-130)$ & 0.72 \\
\hline Cross-clamp (min) & $78(62-98)$ & $78(54-120)$ & $78(71-94)$ & 0.97 \\
\hline \multicolumn{4}{|l|}{ Type of the valve } & \multirow{6}{*}{0.88} \\
\hline St. Jude & $19(65.5 \%)$ & $12(66.7 \%)$ & $7(63.6 \%)$ & \\
\hline Carbomedics & $6(20.7 \%)$ & $4(22.2 \%)$ & $2(18.2 \%)$ & \\
\hline St. Jude aorta & $2(6.9 \%)$ & $1(5.6 \%)$ & $1(9.1 \%)$ & \\
\hline On-X & $1(3.5 \%)$ & $1(5.6 \%)$ & 0 & \\
\hline Tissue & $1(3.5 \%)$ & 0 & $1(9.1 \%)$ & \\
\hline Supra-annular position & $6(20.7 \%)$ & $5(27.8 \%)$ & $1(9.1 \%)$ & 0.36 \\
\hline
\end{tabular}

Table 1. Preoperative and operative data. Continuous data were presented as median (25th-75th percentiles) and categorical data as number (\%). $A V$ atrioventricular, $C P B$ cardiopulmonary bypass, $M R$ mitral regurgitation, $M V$ mitral valve, $P H T$ pulmonary hypertension. ${ }^{\star}$ Other diagnosis: prior mitral valve repair or replacement.

\section{Discussion}

Mitral valve replacement in infants and children is still a challenging procedure. The challenge arises from the unavailability of valve sizes, variable anatomy, the need for chronic anticoagulation, and child growth. Currently, 


\begin{tabular}{|c|c|c|c|c|}
\hline Postop data & All patients $(n=29)$ & Age $\leq 24$ months $(n=18)$ & Age $>24$ months $\leq 60(n=11)$ & $\mathbf{P}$ \\
\hline PHT & $1(3.5 \%)$ & $1(5.6 \%)$ & 0 & $>0.99$ \\
\hline Postop inotropes & $17(58.7 \%)$ & $11(64.7 \%)$ & $6(54.6 \%)$ & 0.70 \\
\hline Hemothorax & $2(6.9 \%)$ & $1(5.9 \%)$ & $1(9.1 \%)$ & $>0.99$ \\
\hline Renal failure & $1(3.5 \%)$ & $1(5.9 \%)$ & 0 & $>0.99$ \\
\hline Respiratory failure & $1(3.5 \%)$ & $1(5.9 \%)$ & 0 & $>0.99$ \\
\hline Sepsis & $6(20.7 \%)$ & $4(23.5 \%)$ & $2(18.2 \%)$ & $>0.99$ \\
\hline Heart block & $7(24.1 \%)$ & $6(35.3 \%)$ & $1(9.1 \%)$ & 0.19 \\
\hline PPM & $6(20.7 \%)$ & $5(29.4 \%)$ & $1(9.1 \%)$ & 0.36 \\
\hline \multicolumn{4}{|l|}{ Thrombosis } & \multirow{4}{*}{$>0.99$} \\
\hline Valve & $3(10.3 \%)$ & $2(11.1 \%)$ & $1(9.1 \%)$ & \\
\hline LV clot & $1(3.5 \%)$ & $1(5.6 \%)$ & 0 & \\
\hline Stroke & $2(6.9 \%)$ & $1(5.6 \%)$ & $1(9.1 \%)$ & \\
\hline ECMO & $1(3.5 \%)$ & $1(5.6 \%)$ & 0 & $>0.99$ \\
\hline \multicolumn{4}{|l|}{ Bleeding } & \multirow{6}{*}{0.35} \\
\hline Subdural & $3(10.3 \%)$ & $2(11.1 \%)$ & $1(9.1 \%)$ & \\
\hline Parenchymal & $2(6.9 \%)$ & $2(11.1 \%)$ & 0 & \\
\hline Surgical & $2(6.9 \%)$ & 0 & $2(18.2 \%)$ & \\
\hline Joints & $1(3.5 \%)$ & 0 & $1(9.1 \%)$ & \\
\hline Minor & $7(24.1 \%)$ & $5(27.8 \%)$ & $2(18.2 \%)$ & \\
\hline Hospital stay, days & $14(10-34)$ & $14(8-32)$ & $16.5(11.5-29.5)$ & 0.79 \\
\hline Tracheostomy & 0 & 0 & 0 & \\
\hline MV peak gradient & $10(6-14)$ & $9(6-12)$ & $12(9-19)$ & 0.35 \\
\hline MV mean gradient & $4(3-7)$ & $3(2-6)$ & $6(4-9)$ & 0.17 \\
\hline LVOTO & $4(13.8 \%)$ & $1(5.6 \%)$ & $3(27.3 \%)$ & 0.14 \\
\hline \multicolumn{4}{|l|}{ LV function } & \multirow{5}{*}{0.58} \\
\hline Fair/good & $19(65.5 \%)$ & $10(55.6 \%)$ & $9(81.8 \%)$ & \\
\hline Mild depressed & $3(10.3 \%)$ & $2(11.1 \%)$ & $1(9.1 \%)$ & \\
\hline Moderately depress & $4(13.8 \%)$ & $3(16.7 \%)$ & $1(9.1 \%)$ & \\
\hline Severely depressed & $3(10.3 \%)$ & $3(16.7 \%)$ & 0 & \\
\hline Hospital mortality & $2(6.9 \%)$ & $2(11.1 \%)$ & 0 & 0.51 \\
\hline
\end{tabular}

Table 2. Postoperative outcomes. ECMO extracorporeal membrane oxygenation, $L V$ left ventricle, $L V O T O$ left ventricular outflow tract obstruction, $P H T$ pulmonary hypertension, $M V$ mitral valve, $P P M$ permanent pacemaker.

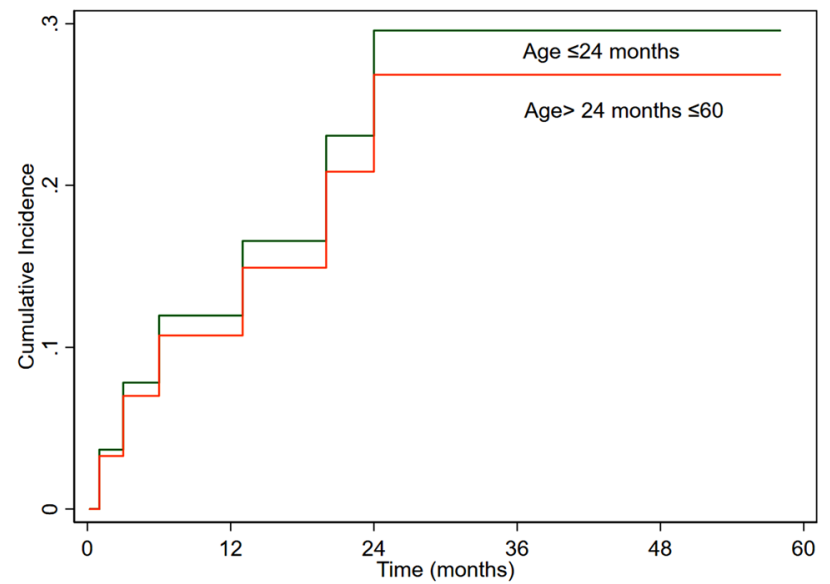

Figure 1. Cumulative incidence of mitral valve reoperation according to age. 


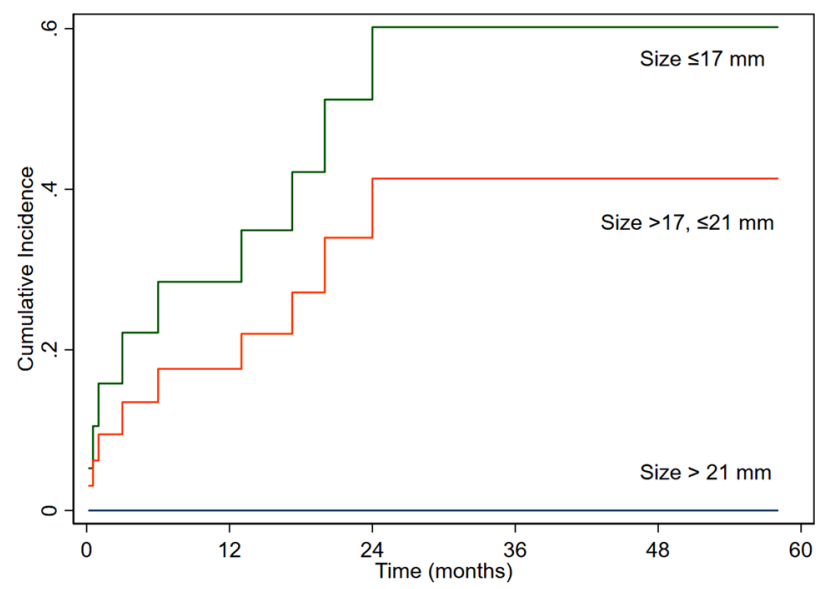

Figure 2. Cumulative incidence of mitral valve reoperation according to valve size.

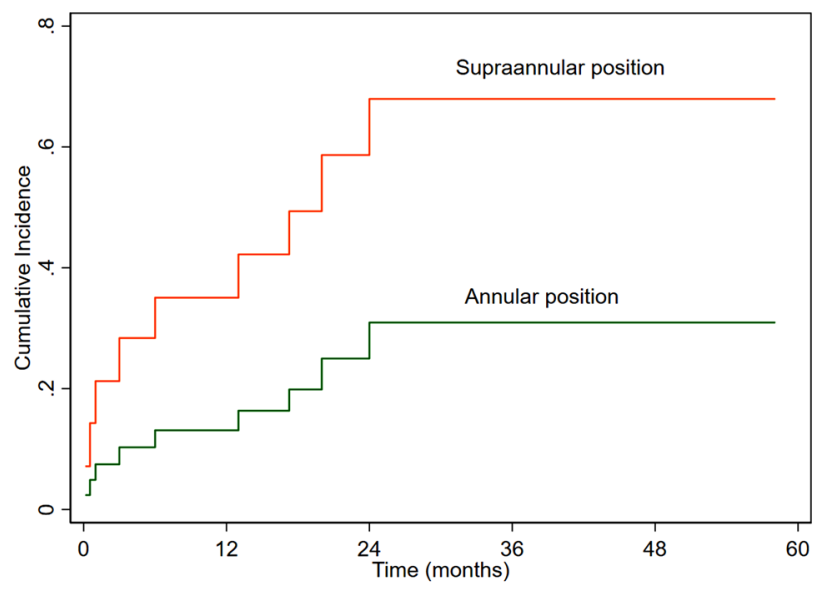

Figure 3. Cumulative incidence of mitral valve reoperation according to the valve position.

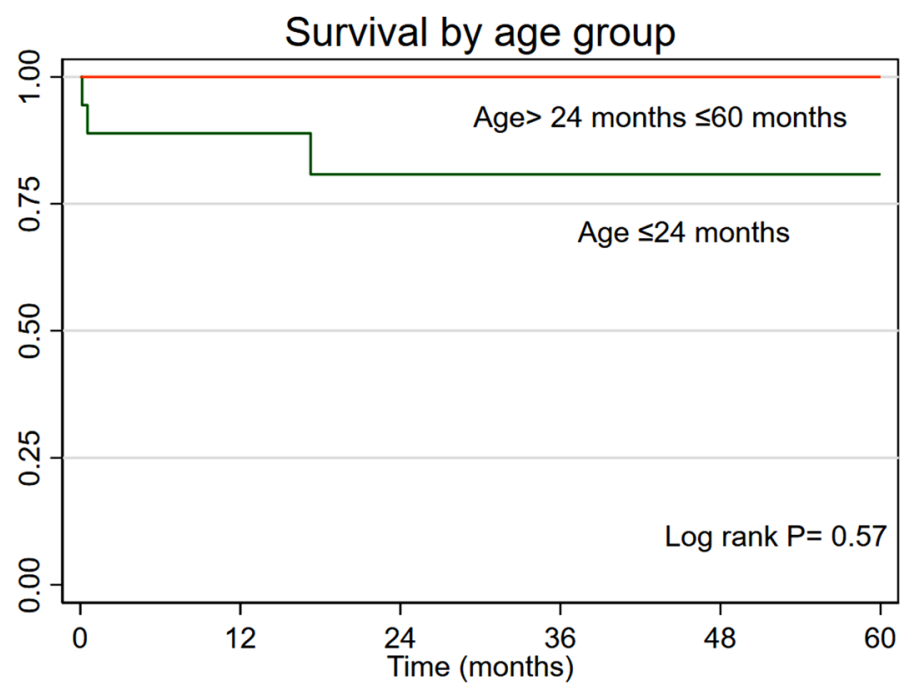

Number at risk

Age $\leq 24$ months 18

Age $>24$ months 11

12

9

9

8

7

7

Figure 4. Kaplan-Meier survival curves according to age. 


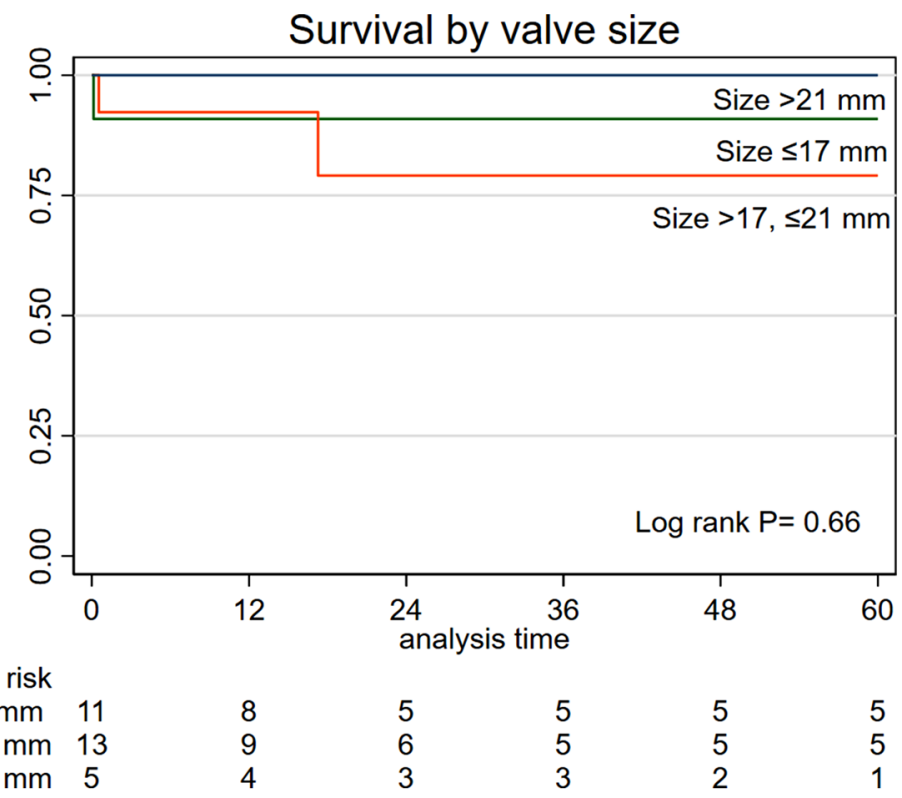

Figure 5. Kaplan-Meier survival curves according to valve size.

valve repair is the standard procedure for surgical management of mitral valve diseases in children, and it is associated with low morbidity and better survival compared to $\mathrm{MVR}^{6}$. However, MVR remains a high-risk procedure with operative mortality rates of $0-36 \%{ }^{4,7,8}$, despite the recent advances in surgical techniques and valves available. In addition, previous studies had shown increased mortality after MVR in children less than 5 years, and this mortality rate was even higher in children less than 2 years ${ }^{9,10}$.

The first challenge is the choice of adequate valve size for this critical age group. Supra-annular valve position is a surgical option to place a large-sized valve in children ${ }^{11}$. Another option suggested by Pluchinotta and colleagues is the stented bovine jugular vein graft (Melody valve) in the mitral position, which was found to be safe, effective, and reproducible, especially in small infants with the possibility of balloon dilatation later in life. However, at least in the short term, the morbidity and mortality risks are comparable to that of a mechanical prosthesis $^{12}$.

Our study reported an overall mortality rate of MVR of $14 \%$, which is similar to that reported by Henaine and associates with a similar number of patients and a mortality rate of $17 \%{ }^{13}$. Caldarone and coworkers reported a mortality rate of $18 \%$ in the same age group 5 . However, our study's mortality rate was less compared to Selamet Tierney and associates, who reported a mortality rate of $39 \%{ }^{14}$. The variability of mortality rates in the literature could be attributed to the included patients' age differences. In a study by Rafii and associates, age younger than 2 years was not associated with increased mortality risk after $\mathrm{MVR}^{15}$. Other factors that may have affected the survival are the valve size or position. In our study, the valve size or position did not affect the survival rate, which could be attributed to the small sample size. In another study, mortality was higher after MVR in children less than 2 years old ${ }^{16}$.

In our study, there was no correlation between valve size, age, or body surface area. This finding could be due to the unavailability of small valve sizes, and the adjustment of the valve size for different ages and weights was made by choice of valve position. We used the supra-annular position more frequently in infants less than 24 months old compared to the older age group. Supra-annular valve position was used in $20 \%$ of our study patients and was associated with an increased risk of reoperation but did not affect postoperative heart block. Selamet Tierney and coworkers used supra-annular position in 33\% of cases with less risk of complete heart block but worse survival than the annular position ${ }^{14}$. Kanter and associates found that supra-annular position was not associated with postoperative heart block but had a high reoperation rate and pulmonary vein stenosis predicted the worse outcomes ${ }^{17}$.

The most common valve used in our study was St. Jude in $66 \%$ of cases. Selamet Tierney and colleagues reported the use of the St. Jude valve in $49 \%$ of cases and Carbomedics in $15 \%$ of cases $^{14}$. Moreover, Caldarone and associates reported St Jude valve use in $79 \%$ of cases and Carbomedics in $7 \%$ of cases 5 . In our study, the size of MV used was less than $17 \mathrm{~mm}$ in 38\%, 17-21 $\mathrm{mm}$ in $45 \%$, and more than $21 \mathrm{~mm}$ in $17 \%$ of cases. The valve size in Selamet Tierney and coworkers' study was less than $17 \mathrm{~mm} \mathrm{41 \% ,17-21} \mathrm{mm} \mathrm{32 \% ,} \mathrm{more} \mathrm{than} 21 \mathrm{~mm} 27 \%$ of cases $^{14}$.

Indication for mechanical mitral valve replacement was $66 \%$ for MR, $10 \%$ for MS, and $24 \%$ for combined, similar to Caldarone et al., who reported MVR 65\% for MR, 9\% for MS, and 26\% for combined ${ }^{5}$. The most common cause of MVR was congenital mitral valve disease, followed by Shone's complex. The etiological diagnosis may affect the outcomes after $\mathrm{MVR}^{18}$; however, we did not observe any effect in our study.

The postoperative heart block requiring pacemaker implantation in our study occurred in five patients (17\%), which is comparable to Henaine and associates who reported heart block in four patients $(14 \%)^{13}$. A similar rate 
was reported by Selamet Tierney and associates, where pacemaker implantation was required in $18 \%$ of patients ${ }^{14}$. Caldarone and coworkers in a similar age group reported the need for pacemaker insertion in $16 \%$ of cases ${ }^{5}$.

The non-significantly higher LVOT pressure in older age groups can be explained by the presence of more patients with Shone's complex in this group, with undersized LVOT as part of their pathology.

Our study did not find a significant effect of age, weight, and valve type on the risk of reoperation; however, the smaller valve size was associated with a higher risk of reoperation. In the study by Henaine and associates, they reported a higher risk of reoperation with younger age, lower weight, Shone's syndrome, smaller prosthesis, and prosthesis other than St. Jude ${ }^{13}$.

Our study is limited with the small sample size; however, mitral valve replacement in this age group is a rare procedure. In addition, the small sample size limited the statistical analysis, and several risk factors could have affected the outcomes and were not included in the analysis. Another limitation is the retrospective design with referral and selection biases. Moreover, the study is a single-center experience, and the generalization of the results needs further multi-center evaluation.

\section{Conclusion}

Mitral valve replacement in children is associated with low morbidity and mortality, and the risk of reoperation could be affected by the valve size and position rather than the age.

\section{Data availability}

Patient data is available upon request with the corresponding author.

Received: 27 February 2021; Accepted: 15 July 2021

Published online: 27 July 2021

\section{References}

1. Mater, K. et al. Patient-specific approach to mitral valve replacement in infants weighing 10 kilograms or less. World J. Pediatr. Congenit. Heart Surg. 10(3), 304-312 (2019).

2. Metras, A., Seguela, P.-E. \& Roubertie, F. Mechanical mitral valve replacement in children: An update. Transl. Pediatr. 8, 455-457 (2019).

3. Raghuveer, G. et al. Predictors of prosthesis survival, growth, and functional status following mechanical mitral valve replacement in children aged <5 years, a multi-institutional study. Circulation 108(Suppl), II174-II179 (2003).

4. Yoshimura, N. et al. Surgery for mitral valve disease in the pediatric age group. J. Thorac Cardiovasc. Surg. 118(1), 99-106 (1999).

5. Caldarone, C. A. et al. Long-term survival after mitral valve replacement in children aged $<5$ years: A multi-institutional study. Circulation 104(12 Suppl 1), I143-I147 (2001).

6. Baird, C. W., Myers, P. O., Marx, G. \& Del Nido, P. J. Mitral valve operations at a high-volume pediatric heart center: Evolving techniques and improved survival with mitral valve repair versus replacement. Ann. Pediatr. Cardiol. 5(1), 13-20 (2012).

7. Choi, P. S. et al. Revisiting prosthesis choice in mitral valve replacement in children: Durable alternatives to traditional bioprostheses. J. Thorac. Cardiovasc. Surg. [Internet] 161(1), 213-225.e3. https://doi.org/10.1016/j.jtcvs.2020.04.173 (2021).

8. Alsoufi, B. et al. Results after mitral valve replacement with mechanical prostheses in young children. J. Thorac. Cardiovasc. Surg. [Internet] 139(5), 1189-1196.e2. https://doi.org/10.1016/j.jtcvs.2009.10.038 (2010).

9. Vohra, H. A. et al. Predicting the performance of mitral prostheses implanted in children under 5 years of age. Eur. J. Cardio-thorac. Surg. Off. J. Eur. Assoc. Cardio-thorac. Surg. 29(5), 688-692 (2006).

10. Beierlein, W. et al. Long-term follow-up after mitral valve replacement in childhood: poor event-free survival in the young child. Eur. J. Cardio-thorac. Surg. Off. J. Eur. Assoc. Cardio-thorac. Surg. 31(5), 860-865 (2007).

11. Barker, C. L., Daubeney, P. E. F. \& Shinebourne, E. A. Complications of supra-annular mitral valve placement in infants. Heart 91(6), e48 (2005).

12. Pluchinotta, F. R. et al. Surgical atrioventricular valve replacement with melody valve in infants and children. Circ. Cardiovasc. Interv. 11(11), e007145 (2018).

13. Henaine, R., Roubertie, F., Vergnat, M. \& Ninet, J. Valve replacement in children: A challenge for a whole life. Arch. Cardiovasc. Dis. 105(10), 517-528 (2012).

14. Selamet Tierney, E. S. et al. Mitral valve replacement in infants and children 5 years of age or younger: Evolution in practice and outcome over three decades with a focus on supra-annular prosthesis implantation. J. Thorac. Cardiovasc. Surg. 136(4), 954-961. e1-3 (2008).

15. Rafii, D. Y., Davies, R. R., Carroll, S. J., Quaegebeur, J. M. \& Chen, J. M. Age less than two years is not a risk factor for mortality after mitral valve replacement in children. Ann. Thorac. Surg. [Internet] 91(4), 1228-1234. https://doi.org/10.1016/j.athoracsur. 2010.11.058 (2011).

16. Ibezim, C. et al. Outcomes of mechanical mitral valve replacement in children. Ann. Thorac. Surg. [Internet] 107(1), 143-150. https://doi.org/10.1016/j.athoracsur.2018.07.069 (2019).

17. Kanter, K. R., Kogon, B. E. \& Kirshbom, P. M. Supra-annular mitral valve replacement in children. Ann. Thorac. Surg. [Internet] 92(6), 2221-2229. https://doi.org/10.1016/j.athoracsur.2011.06.023 (2011).

18. Elmahrouk, A. F. et al. Outcomes of biventricular repair for shone's complex. J. Card. Surg. 36, 12-20 (2020).

\section{Author contributions}

A.E., M.M, A.A and M.I, designed the study, A.E and M.M. conceived and planned the study, A.E. , M.M, and R.A. involved in the data curation M.M. and R.A. conducted the literature review, A.A. and M.I. performed the statistical analysis. A.E, A.A, H.B, M.S. and A.J performed analysis and interpretation of data, A.E., H.B., M.S. and A.J supervised the study, A.A., M.M and R.A drafted the manuscript. All authors discussed the results, reviewed the manuscript and approved the final version.

\section{Competing interests}

The authors declare no competing interests. 


\section{Additional information}

Correspondence and requests for materials should be addressed to A.F.E.

Reprints and permissions information is available at www.nature.com/reprints.

Publisher's note Springer Nature remains neutral with regard to jurisdictional claims in published maps and institutional affiliations.

(c) (1) Open Access This article is licensed under a Creative Commons Attribution 4.0 International License, which permits use, sharing, adaptation, distribution and reproduction in any medium or format, as long as you give appropriate credit to the original author(s) and the source, provide a link to the Creative Commons licence, and indicate if changes were made. The images or other third party material in this article are included in the article's Creative Commons licence, unless indicated otherwise in a credit line to the material. If material is not included in the article's Creative Commons licence and your intended use is not permitted by statutory regulation or exceeds the permitted use, you will need to obtain permission directly from the copyright holder. To view a copy of this licence, visit http://creativecommons.org/licenses/by/4.0/.

(C) The Author(s) 2021 